\title{
Climate and health benefits of rapid coal-to-gas fuel switching in the U.S. power sector offset methane leakage and production cost increases
}

\author{
Thomas A. Deetjen ${ }^{*, \dagger}$ and Inês L. Azevedo $\ddagger$ \\ $\dagger$ Center for Electromechanics, University of Texas, Austin, TX 78758, USA \\ $\ddagger$ Department of Energy Resources Engineering, Stanford University, Stanford, CA 94305, USA \\ E-mail: t.deetjen@cem.utexas.edu
}

11 pages in length

Tables:

Table S1: Baseline coal generation-i.e., at 0\% redispatch—per NERC Region.

Table S2: Optimal solution for $\mathrm{GWP}_{100}$.

Table S3: Annual error per region for the 2017 version of the dispatch model.

Figures:

Fig S1: Map of the different North American Reliability Corporation (NERC) electric grid regions.

Fig S2: Results for the RFC, SERC, WECC, and TRE regions.

Fig S3: Results for the SPP, MRO, and FRCC regions.

Fig S4: Regional abatement production cost and avoided GHG emission curves.

Fig S5: Regional production cost and GHG emissions curves.

Fig S6: Sensitivity analysis of redispatch goals for $\mathrm{GWP}_{100}$.

Fig S7 Relative error between the dispatch model and historical emissions data.

Fig S8 Dispatch model total emissions vs total online fossil generation capacity in 2017. 


\section{NERC regions map and baseline gas and coal}

Fig S1 shows a map of the different NERC regions. We simulate seven of the NERC regions. We exclude the NPCC region because its baseline coal generation is nearly zero. Table S1 shows the baseline ( $0 \%$ redispatch) gas and coal capacity and generation in the 2017 simulation model.

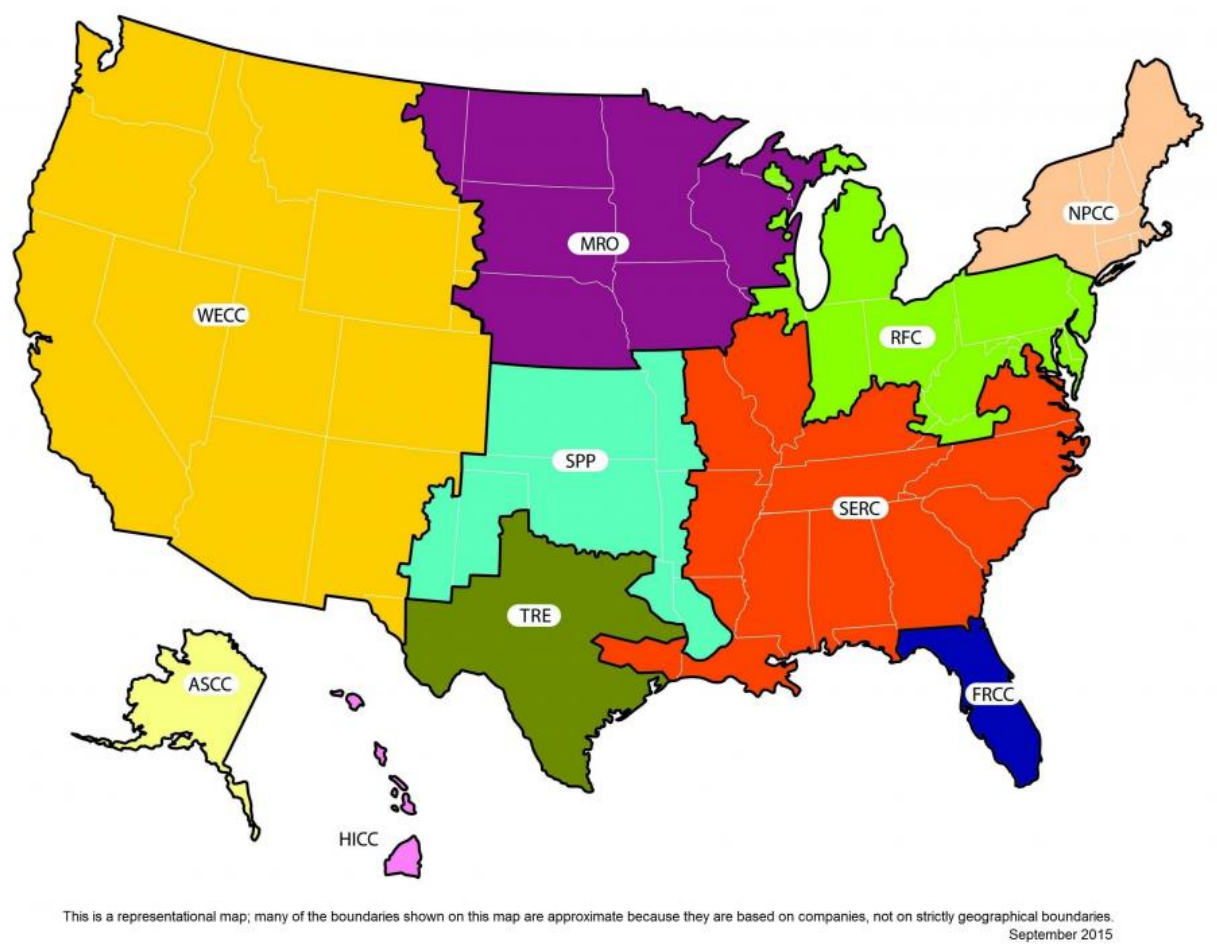

Figure S1: Map of the different electric grid regions defined by the North American Reliability Corporation (NERC). Image courtesy of the Environmental Protection Agency. ${ }^{1}$

Table S1: Baseline Coal Generation - i.e., at 0\% redispatch—per modeled NERC Region.

$\begin{array}{lrrrrrrr}\text { NERC Region Baseline } & \text { RFC } & \text { SERC } & \text { WECC } & \text { TRE } & \text { SPP } & \text { MRO } & \text { FRCC } \\ \text { Coal Capacity [GW] } & 85.4 & 85.4 & 32.3 & 20.9 & 19.4 & 20.4 & 7.6 \\ \text { Nat. Gas Combined Cycle Capacity [GW] } & 31.9 & 58 & 43 & 32.5 & 13.1 & 4.9 & 27 \\ \text { Nat. Gas Other Capacity [GW] } & 43.7 & 67.7 & 23.6 & 19.3 & 21.1 & 8.8 & 12.4 \\ \text { Coal Generation [TWh] } & 360 & 300 & 200 & 120 & 100 & 115 & 25 \\ \text { Natural Gas Generation [TWh] } & 195 & 380 & 160 & 145 & 55 & 25 & 150\end{array}$




\section{Region-specific results}

The following results use $\mathrm{GWP}_{20}$ for methane. Figs $\mathrm{S} 2$ and $\mathrm{S} 3$ show additional results at the regional-scale. Fig S2 includes the largest four regions-RFC, SERC, WECC, and TRE. Fig S3 includes the three smallest regions-SPP, MRO, FRCC.
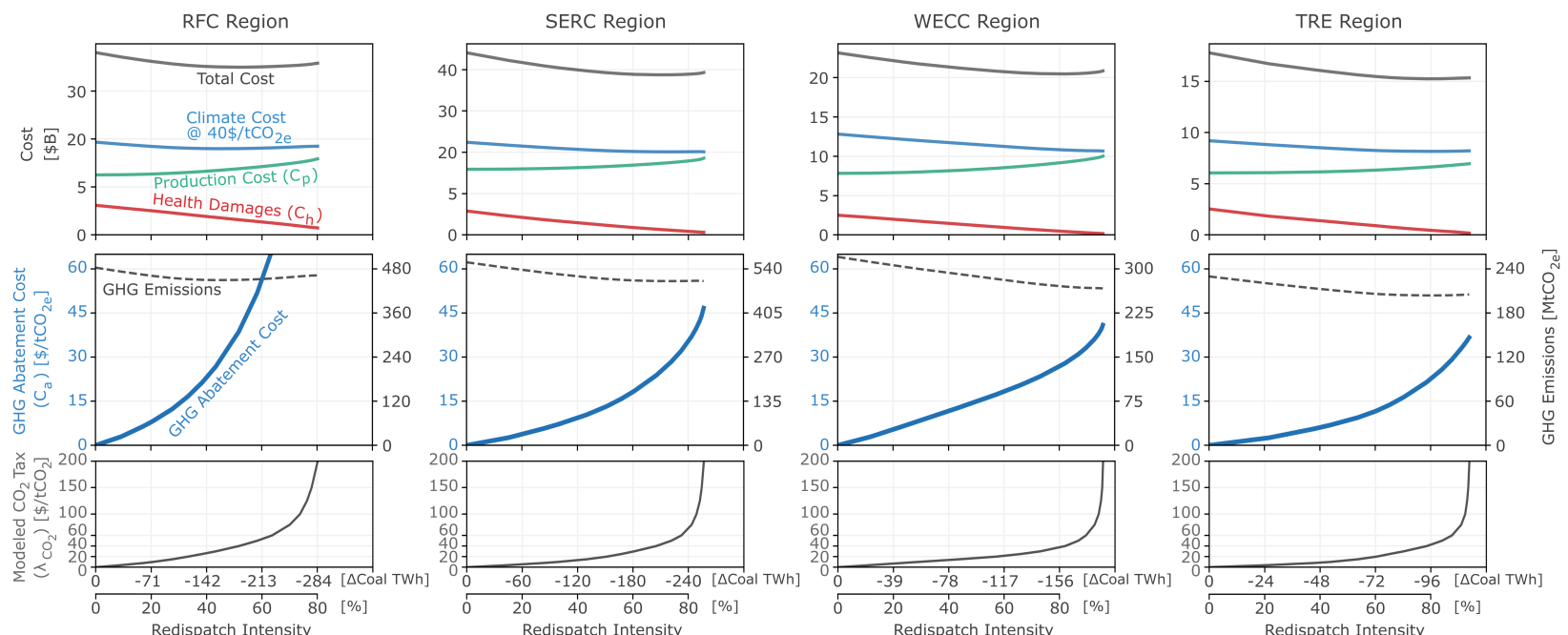

Figure S2: Results for the RFC, SERC, WECC, and TRE regions. The horizontal axis shows the percentage by which coal electricity generation is reduced from the 2017 baseline. Top: As coal-to-gas fuel switching increases, production cost grows exponentially, health damages fall linearly, and climate cost (GHG emissions times a $40 \$ /$ tCO2e social cost of carbon) exhibits a convex curve. Middle: The GHG abatement production costs-i.e. the change in production cost (excluding the $\mathrm{CO} \neg 2$ tax) divided by the change in GHG emissions (including methane leakage) from the 2017 baseline-grows exponentially. Total GHG emissions (including methane leakage) decrease quickly at first but eventually bottom out. Bottom: To force greater intensities of coal-to-gas fuel switching, we input exponentially higher CO2 taxes into the dispatch model.

Regional findings resemble the national-scale conclusions. Each NERC region can cite health benefits to justify major redispatch, as shown in Fig S4. The redispatch scope-its maximum reduction in coal electricity generation, maximum avoided GHG emissions, and GHG abatement production cost curve-however, varies greatly by region. For different regions, the optimal redispatch intensity varies from $35-85 \%$.

The abatement production cost curve's efficiency and magnitude both vary by region. If we mandate a $4 \%$ GHG reduction per region, for example, the average abatement production 

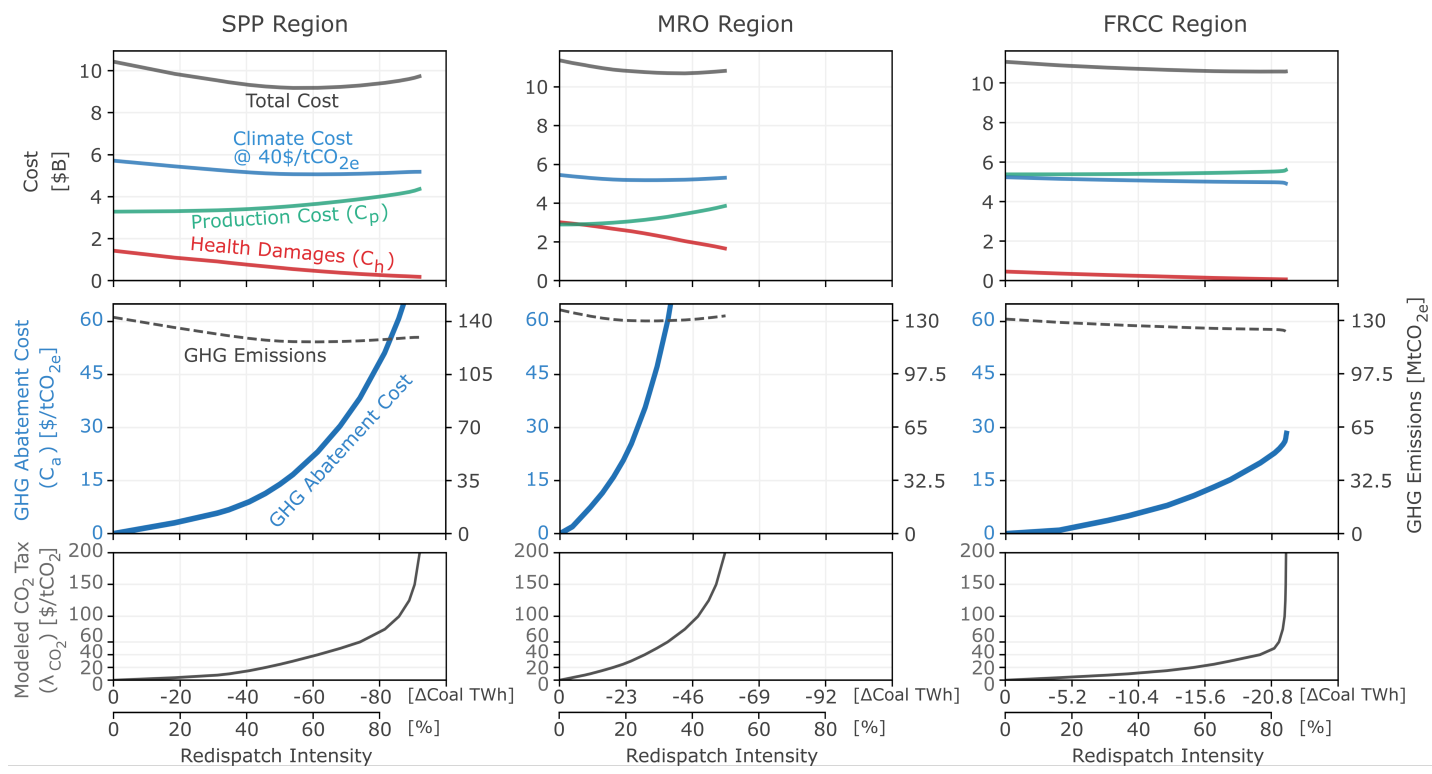

Figure S3: Results for the SPP, MRO, and FRCC regions. The horizontal axis shows the percentage by which coal electricity generation is reduced from the 2017 baseline. Top: As coal-to-gas fuel switching increases, production cost grows exponentially, health damages fall linearly, and climate cost (GHG emissions times a $40 \$ / \mathrm{tCO} 2 \mathrm{e}$ social cost of carbon) exhibits a convex curve. Middle: The GHG abatement production costs - i.e. the change in production cost (excluding the $\mathrm{CO} \neg 2$ tax) divided by the change in GHG emissions (including methane leakage) from the 2017 baseline - grows exponentially. Total GHG emissions (including methane leakage) decrease quickly at first but eventually bottom out. Bottom: To force greater intensities of coal-to-gas fuel switching, we input exponentially higher CO2 taxes into the dispatch model. 
costs range from 2-15\$/ $\mathrm{tCO}_{2 e}$. To force the redispatch needed to achieve that $4 \% \mathrm{GHG}$ reduction, we input $\mathrm{CO}_{2}$ taxes ranging from $4-20 \$ / \mathrm{tCO}_{2}$ into our model. Similarly, the maximum possible avoided GHG emissions varies regionally, ranging from $5-17 \%$ below the 2017 baseline.
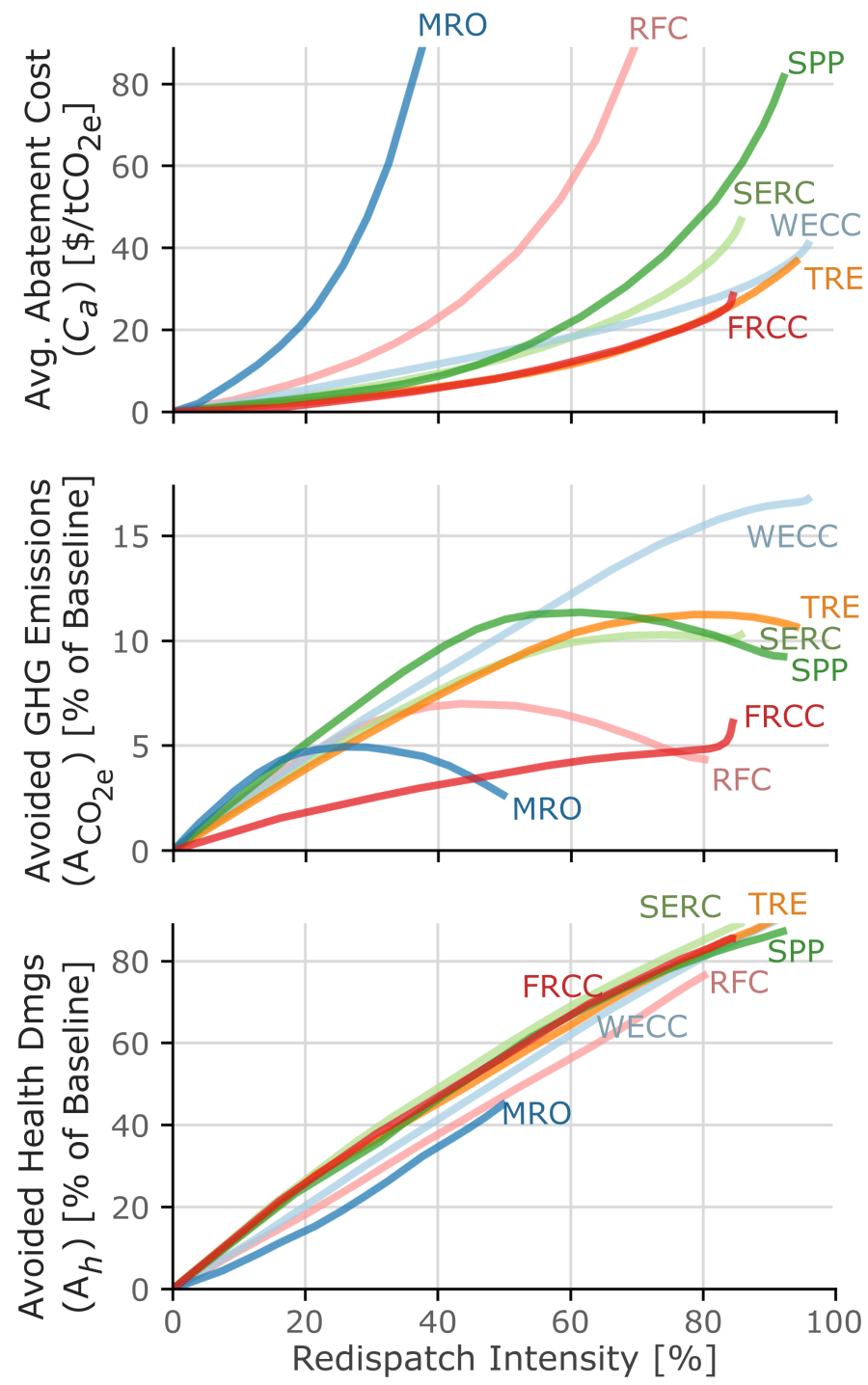

Figure S4: Abatement production cost and avoided GHG emissions curves vary significantly among NERC regions. All regions, however, show a similar linear relationship between coal electricity generation and avoided health damages.

These regional differences are elaborated in Fig S5. Each region shows a non-linear Pareto front ${ }^{2}$ between total production cost and exhaust stack $\mathrm{CO}_{2}$ emissions; initial redispatch greatly reduces $\mathrm{CO}_{2}$ exhaust at a low abatement production cost, but increased redispatch 
has diminishing returns. Methane leakage complicates this relationship, but some regions still show flatter, longer, cost-to-emissions curves than others. The three largest regions-SERC, RFC, and WECC - comprise $71 \%$ of the GHG reductions achieved by the optimal national-scale redispatch. Refer to the SI for additional data on cost, GHG emissions, GHG abatement production cost, and modeled $\mathrm{CO}_{2}$ taxes for each region's redispatch analysis.

National policy must acknowledge these regional differences. Each region's redispatch incurs unique costs and health benefits; their ability to contribute to national emissions goals varies. Equitable national fuel-switching targets must have region-specific goals.
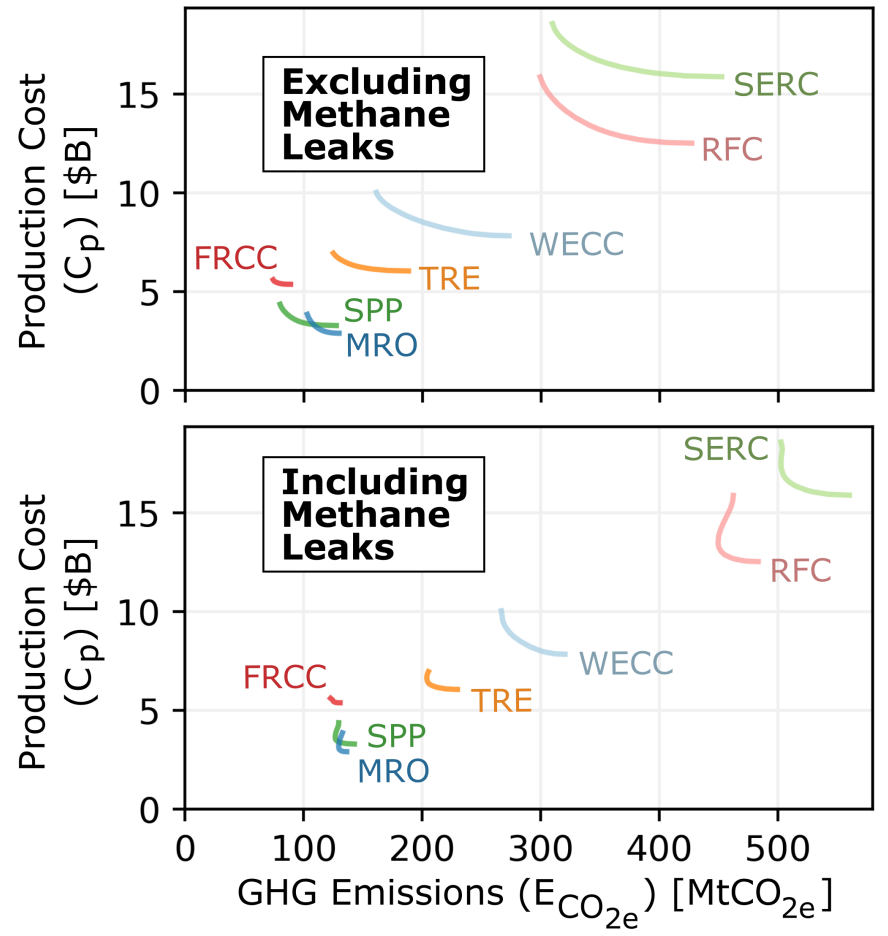

Figure S5: Each region shows a non-linear Pareto front between production cost and $\mathrm{CO}_{2 e}$ emissions; initial redispatch greatly reduces GHG emissions at a low total production cost increase, but increased redispatch becomes very costly. 


\section{Additional Results under 100-year Global Warming Potential Time Scale}

In this section, we recalculate the results shown in Figures 3 and 7 in the main article using a global warming potential (GWP) timescale of 100 years instead of 20 years. Refer to the "Quantifying GHG emissions" portion of the Methods section for a discussion of GWP. Figure S6 presents a sensitivity analysis of how the redispatch solution changes whenever we change the overall objective. Like Figure 6 in the main article, Fig S6 shows the impact of omitting production cost, methane leakage, health damages, or climate damages from the redispatch objective. It shows these findings for various methane leakage rates. The findings in Fig S6 reach similar conclusions as the findings in the main article:

- Ignoring production cost, methane leakage, health damages, or climate damages yields a suboptimal solution compared to the default.

- Ignoring production cost or methane leakage yields too much redispatch.

- Ignoring health damages or climate damages yields too little redispatch.

- Reducing methane leakage rates benefits both solutions.

However there are three important differences. First, in these $\mathrm{GWP}_{100}$ findings, ignoring climate damages always yields too little redispatch. This relationship in the $\mathrm{GWP}_{20}$ findings is more nuanced. Second, while the $\mathrm{GWP}_{20}$ Ignore Climate scenario tracked most closely to the $\mathrm{GWP}_{20}$ Default solution, the $\mathrm{GWP}_{100}$ Default is closer to the $\mathrm{GWP}_{100}$ Ignore Methane scenario. Third, the $\mathrm{GWP}_{100}$ default solution always calls for more redispatch than the $\mathrm{GWP}_{20}$ default solution. In short, the $\mathrm{GWP}_{100}$ solution is less influenced by methane leakage. It also anticipates greater climate benefits from coal-to-gas redispatch. The optimal solution for each GWP scenario is shown in Table S2. Given that both solutions minimize their respective total cost, the relevant question may be whether we 

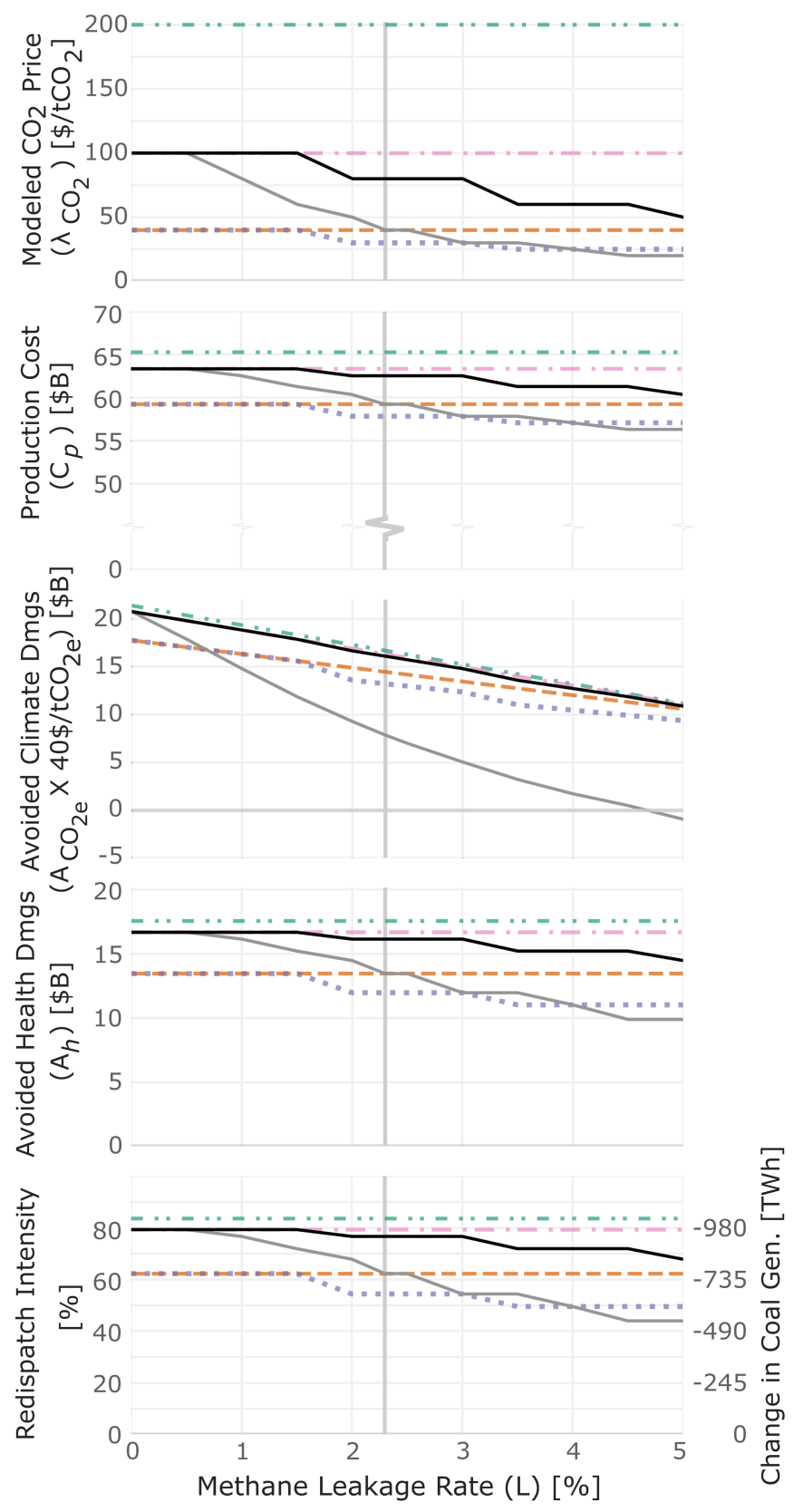

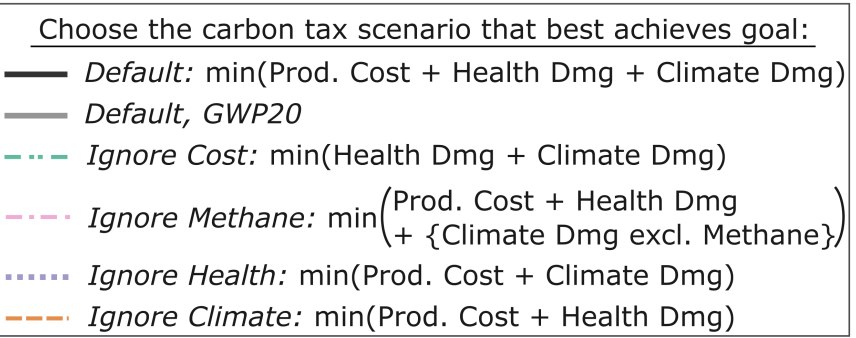

Figure S6: By adjusting the objective, the optimal redispatch solution changes. This figure presents the same sensitivity analysis discussed in Figure 6 of the main article. For comparison, it also includes the default solution for the $\mathrm{GWP}_{20}$ analysis. 
prefer a power sector with 1240 MtCO2 and 6.74 Mt methane (GWP20), or one with 1180 MtCO2 and 7.61 Mt methane. The answer depends on the GWP time scale.

Table S2: Optimal solutions at $2.3 \%$ methane leakage for the $\mathrm{GWP}_{20}$ and $\mathrm{GWP}_{100}$ time scales.

$\begin{array}{lrr}\text { Optimal Solution Metric } & \text { GWP }_{20} & \text { GWP }_{100} \\ \text { GWP of Methane } & 84 & 28 \\ \text { Redispatch Intensity [\%] } & 62 & 76 \\ \text { Total Health Damages [\$B] } & 8.4 & 5.7 \\ \text { Total Production Cost [\$B] } & 59.2 & 62.5 \\ \text { CO2 Emissions [Mt] } & 1240 & 1180 \\ \text { Methane Emissions [Mt] } & 6.74 & 7.61\end{array}$

\section{Dispatch model validation}

For a thorough validation of the model, we refer the reader to the authors' previous publication. ${ }^{3}$ For convenience, we reproduce two relevant figures from that study here. Table S3 and Fig S7 show the relative error between the dispatch model output and historical emissions, where the error for pollutant $\mathrm{X}$ equals:

$$
\text { Error }_{X}=\frac{\sum_{t=0}^{8759} X_{\text {historical }}(t)-X_{\text {simulated }}(t)}{\sum_{t=0}^{8759} X_{\text {historical }}(t)}
$$

Fig S8 show the relationship between total emissions and total online fossil fuel generation capacity. In both Figures, the dispatch model accurately reproduces hourly historical emissions.

Table S3: Annual error per region for the 2017 version of the dispatch model.

$\begin{array}{lrrrrrrr}\text { Error of 2017 Model } & \text { RFC } & \text { SERC } & \text { WECC } & \text { TRE } & \text { SPP } & \text { MRO } & \text { FRCC } \\ \text { Total CO2 Emissions [\%] } & 3 & 3 & 3 & 6 & 4 & 4 & 11 \\ \text { Total SO2 Emissions [\%] } & 9 & 10 & 10 & 18 & 13 & 10 & 24 \\ \text { Total NOx Emissions [\%] } & 12 & 11 & 7 & 10 & 14 & 8 & 24 \\ \text { Total Coal Generation [\%] } & 6 & 6 & 8 & 8 & 10 & 6 & 20\end{array}$


Simulated Total Emissions

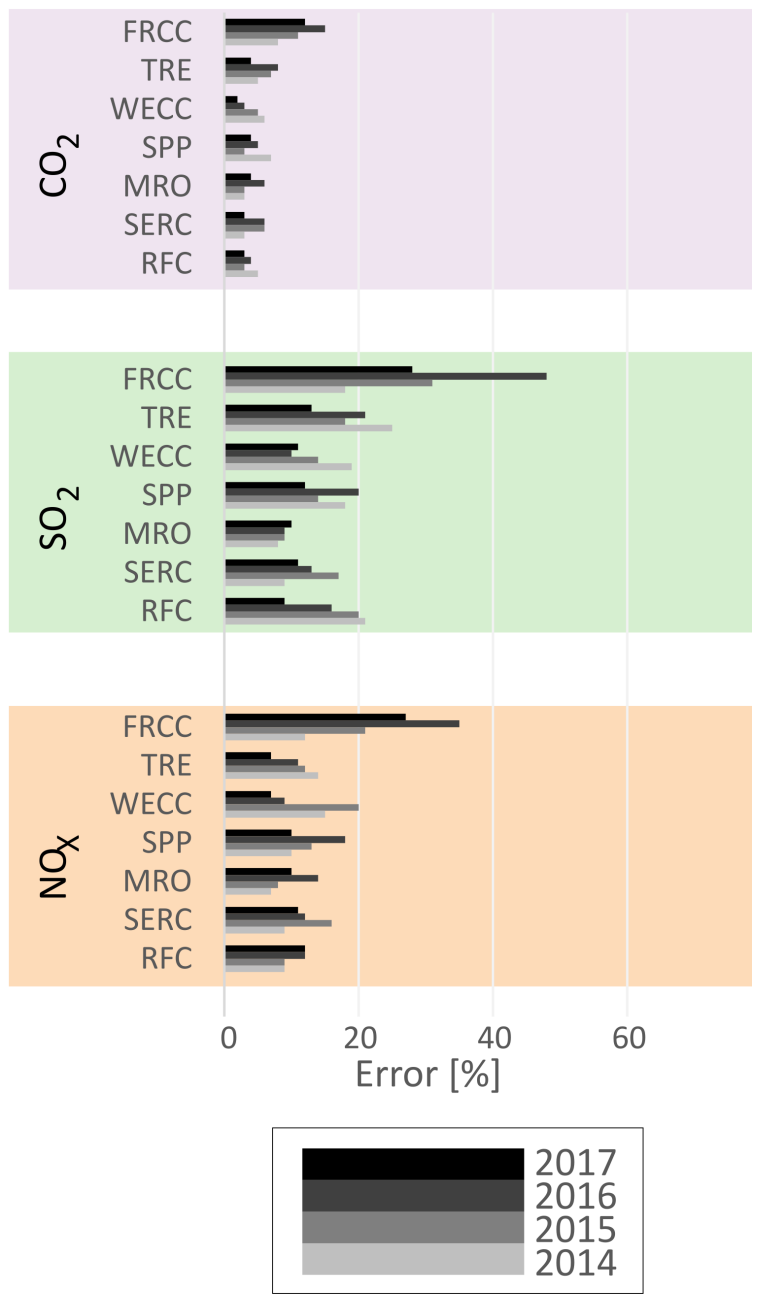

Figure S7: Relative error between the dispatch model and historical emissions data. Reproduced from. ${ }^{3}$ 

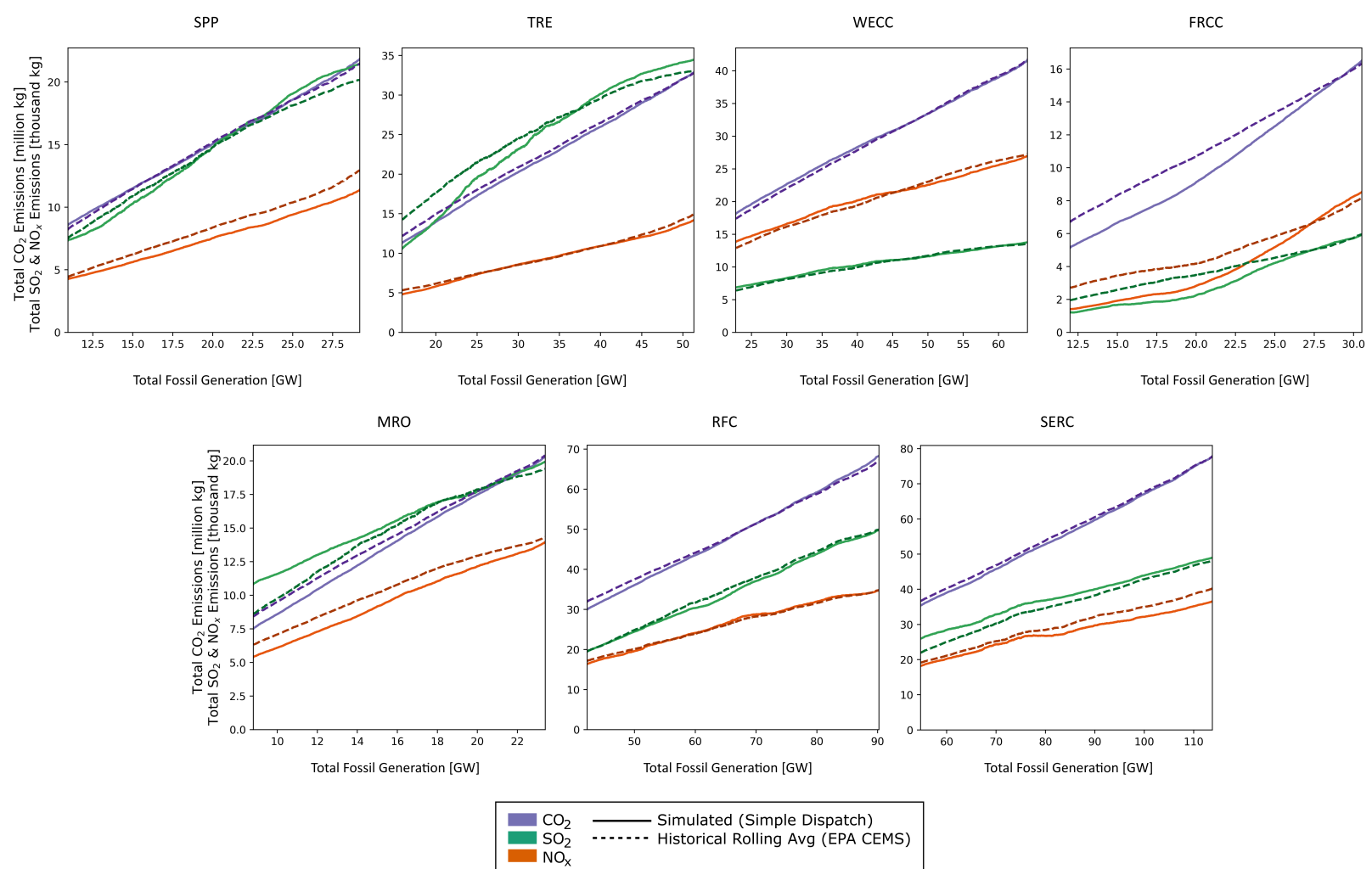

Figure S8: Dispatch model total emissions vs total online fossil generation capacity in 2017. Reproduced from. ${ }^{3}$ 


\section{References}

(1) Regional Map for the North American Reliability Corporation (NERC); Environmental Protection Agency, Washington D.C.; https://www.epa.gov/energy/north-americanreliability-corporation-nerc-region-representational-map.

(2) El-Sehiemy, R. A.; Rizk-Allah, R. M.; Attia, A.-F. Assessment of hurricane versus sine-cosine optimization algorithms for economic/ecological emissions load dispatch problem. International Transactions on Electrical Energy Systems 2019, 29, e2716.

(3) Deetjen, T. A.; Azevedo, I. L. Reduced-Order Dispatch Model for Simulating Marginal Emissions Factors for the United States Power Sector. Environmental science \& technology 2019, 53, 10506-10513. 